\title{
THE VITAMIN MODEL OF WELL-BEING AT WORK - AN APPLICATION IN RESEARCH IN AN AUTOMOTIVE COMPANY
}

\author{
ANNA BORKOWSKA ${ }^{1}$ and AGNIESZKA CZERW ${ }^{2}$ \\ ${ }^{1}$ Wrocław University of Science and Technology, Wrocław, Poland \\ Faculty of Computer Science and Management \\ ${ }^{2}$ SWPS University of Social Sciences and Humanities, Poznań, Poland
}

\begin{abstract}
Objectives: The main aim of the presented study was to check the level of perceived dimensions of work according to Peter Warr's model of wellbeing at work (referred to as the Vitamin Model). The main aim was to verify: a) the non-linear dependency of well-being and the first group of "vitamins" of the model; and b) the linear dependency for the second group of dimensions of work. Material and Methods: The article presents the results of research conducted in a Polish automotive production company. The Vitamin TAW Questionnaire was used to diagnose the dimensions of work. Well-being was measured using the Satisfaction With Job Scale. The analyzes were carried out on a group of 197 people who took part in the research and represented various departments of the organization. Results: The obtained results allow a partial confirmation of the non-linear relationship within the dimensions of the first group (for 3 out of 6 characteristics) and a full confirmation of the linear relationship for all dimensions from the second group. Conclusions: The recommendations arising from the research are universal in character and can be used by managers of various organizations. The results clearly demonstrate the need for reflection, and evidence-based and data driven changes in human resources management, and the creation of positive environment of work. Int J Occup Med Environ Health. 2022;35(2):187-98
\end{abstract}

Key words:

management, well-being, employees, human resources, job characteristics, vitamin model

\section{INTRODUCTION}

In recent decades the concept of well-being, referring to optimal psychological functioning and experience [1], has become key in positive psychology. The discussion on this important concept in psychology and other social sciences has focused on its hedonic and eudaimonic essence since the first publications by Waterman [2], Diener [3], Ryff [4], and Seligman [5]. The first approach associates well-being with happiness, satisfaction, positive emotions and a lack of negative emotions $[1,2,6,7]$. In turn, the tradition of eudaimonic well-being is based on the positive functioning of people, their development, their perceived purpose and meaning, and values and cohesion of their actions $[2,4]$.

In the field of work and organizational psychology, both the concept of well-being and its varied grasp have been present since the beginning of research in the field of positive psychology. The sense of well-being - understood as the optimal functioning and development of an individual in specific areas, and the balance between the individual's personal resources and the requirements and challenges they face - is of particular importance in

Received: February 21, 2020. Accepted: July 22, 2021.

Corresponding author: Anna Borkowska, Wrocław University of Science and Technology, Faculty of Computer Science and Management, Wybrzeże Wyspiańskiego 27, 50-370 Wrocław, Poland (e-mail: anna.borkowska@pwr.edu.pl). 
work settings. In work environments people face challenges and expectations on a daily basis, at the same time managing their resources and counting on support from the organization. Achieving and maintaining well-being is important from the standpoint of both an individual or the whole group, and also from that of the organization. Well-being is associated with work engagement and thus with greater efficiency $[8,9]$.

While constructing a general model of well-being at work, other than deciding about its more eudaimonic or more hedonic character, it is also necessary to consider employees' personal characteristics in addition to environmental aspects [10-13]. Classic models such as the Job Characteristics Model (JCM) by Hackman and Oldham [14] or the Job Demands-Control (JD-C) model by Karasek $[15,16]$, taking into account psychosocial and organizational characteristics of work and their impact on the mental state of employees (health, well-being, stress level), assume linear dependencies. They posit the great importance of work and meaningful feedback (the JCM) and a high degree of autonomy in decision-making as well as work autonomy (the JD-C model). On the other hand, Warr $[13,17,18]$ perceived the relationship between job characteristics and employee well-being in a slightly different way. In his Vitamin Model of well-being, he also assumed curvilinear relationships.

The subject of this article and the research presented herein is using Warr's Vitamin Model of well-being to diagnose a company. As mentioned before, Warr's model assumes a more complex dependency, namely non-linear relationships between well-being and certain dimensions of work. The term "vitamin" refers to the types of nutrients present in organisms that are necessary for human and animal functioning. Their presence in the body or their consumption can only have a positive effect (also known as a "constant effect"). There are also vitamins that, with high levels in the body or excess intake, can produce a negative effect (an "additional decrement").
In publications appearing in recent years, 12 job characteristics were taken into account (6 in each of the discussed groups). The "constant effect" (CE) group includes: financial compensation, physical security at work, valued social position, supportive supervision, career outlook, and equity $[17,18]$. The "additional decrement" (AD) group that leads to a decline in well-being due to excess includes: personal control, opportunity for skill use and acquisition, demands and goals, variety of work, transparency of expectations and evaluation, and level of social contacts.

Warr provided an interesting explanation of the description and diagnosis of features included in the AD group. He indicated that, while such features in themselves might be harmful in excess, they may also be strongly associated with others. This can cause further decline in well-being. For example, extreme diversity of work in itself overloads cognitive resources while, at the same time, preventing the use of skills and employee development.

Warr suggested at least 2 research directions in the described area of diagnosing and strengthening employee well-being. The first is studying the relationship between psychological characteristics of individuals and those of work (occupation, workplace, organization), and the results of employee-work interactions in terms of wellbeing. Another research direction concerns the relations between these job characteristics that are conducive to well-being and efficiency. Rarely, however, these aspects of people's functioning at work are strongly correlated with each other. Also, rare are findings suggesting that the planned scope of work, organizational structures procedures, or interventions in this area bring about an unambiguously positive effect. Changes in the direction of increasing efficiency may deprive people of a sense of security, influence, control, or support from their superiors. On the other hand, introducing high employee autonomy, improving the level of social relations, or taking other measures favoring workers' well-being may - within 
a certain time perspective - come at important costs to the organization.

Despite these needs and claims, the number of studies on the Vitamin Model is not very impressive. The available literature includes papers on model testing in health professionals in the Netherlands $[19,20]$, students of Canadian universities employed temporarily [21], Finnish managers [22], or German horticultural industry workers [11]. Many inconsistencies appeared, probably due to the context in which the individual studies were carried out, the specificity of the participant groups, various well-being measurement tools (emotional, cognitive or based on health indicators), and even different versions of the Vitamin Model of job characteristics. However, it should be emphasized that the results provide convincing evidence of the superiority of non-linear models in the field of research on occupational well-being and its causes on the part of certain job characteristics.

\section{MATERIAL AND METHODS}

\section{Aim of the study}

The main objective of the study was to verify the non-linear dependency of well-being and the $\mathrm{AD}$ group of vitamin features, and a linear dependency for the CE group of job characteristic. Warr's Vitamin Model of well-being [17,18] was adopted as a starting point for the study. The results were expected to indicate if the organization was able to maintain competitive advantage, thanks to the ongoing response to behaviors and reported employee needs, without the need to carry out specific interventions in the organization but only based on organizational diagnosis.

The results of the presented studies should answer the following question: What is the relationship between job characteristics from the $\mathrm{CE}$ group and the $\mathrm{AD}$ group, and the level of employee satisfaction?

Referring to that question, the following hypotheses arising from the assumptions of the Vitamin Model of wellbeing at work can be made:
- H1. The further away from the optimum is the level of job characteristics in the $\mathrm{AD}$ group, the lower the level of well-being (a non-linear dependency).

- H2. The higher the level of job characteristics in the CE group, the higher the level of well-being level.

This direction of the relationship between the analyzed variables is consistent with the concept of positive organization scholarship, which in its assumptions refers, among other things, to the findings of positive psychology [23]. In this approach, the growth of the organization is based on the development and implementation of strategic activities aimed at changing and improving the company's functioning. Particular emphasis is placed on internal human factors within the organization, aimed at ensuring and increasing the level of employee well-being. Changes introduced in the organization, and more specifically in the human resources policy, should aim at changing the perception of job characteristics by employees, and thus influencing their well-being at work [23].

\section{Procedure and methods}

Paper questionnaires were used in the study (see below). The participants filled them out in groups in a conference room provided by the organization. Completed questionnaires were deposited in special boxes accessible only to the researchers.

The employees were assured that their individual answers were confidential. Full anonymity could not be guaranteed, as a comparison of results from 2 measurements was necessary. Under these conditions, employees agreed to participate in the study. Consent was expressed by joining the study. Those employees who did not agree to such a procedure did not complete the questionnaires.

The described study was conducted as part of a commercial project. It was commissioned by a company that was not expected to be approved by the research ethics committee. Consequently, the procedure was consulted in a less formal way with the university's 
research ethics committee. However, no written decision was made. The principal job characteristics were measured using the Vitamin TAW Questionnaire. This questionnaire was constructed at the request of TAW Polska, which is the owner of the property rights of this tool. Therefore, the name of the questionnaire includes the name of the company [24]. This tool is based on the theoretical assumptions of Warr's Vitamin Model of well-being. The questionnaire consists of 12 scales which form 2 groups: AD (the "additional decrement" job characteristics) and CE (the "constant effect" job characteristics).

\section{Dimensions in the AD group}

The following dimensions are used in the $\mathrm{AD}$ group:

- Personal control (PC) $(\alpha=0.78)$ - the scope and freedom of decisions made by an employee concerning their work, the manner and time of its performance and selection of co-workers, as well as the level of personal influence of the employee on the results of their tasks.

- Demanding supervision (DS) $(\alpha=0.79)$ - the ongoing employee supervision by superiors and the evaluation of their tasks based on negative feedback and error tracking.

- Work diversity (WD) ( $\alpha=0.84)$ - the level of diversification (repetitiveness vs. variety) of tasks, methods and places of their execution, flexibility of thinking and employee behavior.

- Workload (WL) ( $\alpha=0.77)$ - feeling tired due to work overload, task difficulty and responsibility for task execution.

- Social contacts intensity (SCI) ( $\alpha=0.83)$ - the frequency and quality of the employee's interpersonal contact with others in the context of their work, e.g., co-workers, supervisors, clients.

- Development and evaluation (DE) $(\alpha=0.93)$ - the importance that employees believe an organization at- taches to their own development, using their potential as well as the organization's involvement in career path planning.

\section{Dimensions in the CE group}

The following dimensions are used in the CE group:

- Supportive supervision (SS) ( $\alpha=0.86)$ - employees' relationships with their superiors based on diverse feedback from results and work methods, the readiness and willingness of supervisors to provide support and assistance, and their knowledge of employees' strengths and weaknesses.

- Sense of security in organization (SSO) $(\alpha=0.79)$ - efforts of the organization to ensure the physical safety of its members and the environment, and providing employees with a sense of dignity, and respect of the organization for their own rights.

- Financial compensation (FC) $(\alpha=0.82)$ - the level of satisfaction with financial remuneration, as well as transparency and fairness of the remuneration policy in the organization.

- Significant social position (SSP) ( $\alpha=0.75)$ - the purpose and usefulness of work for others and the organization, the importance and prestige of the professional role, and a sense of being noticed by others in the organization.

- Organizational ethics $(\mathrm{OE})(\alpha=0.78)$ - involvement of the organization in respecting standards and ethical principles related to risk avoidance, striving for fair and just practices in the organization.

- Career prospects (CP) ( $\alpha=0.80)$ - the clarity of the organization's career planning policies and knowledge of the conditions of promotion and pay, as well as the personal influence of employees on shaping their own careers.

The Vitamin Model of well-being theoretically assumes simply different diagnostic methods for the 2 described vitamin groups (job characteristics). Therefore, when 
constructing the questionnaire - from the very beginning - different methodologies were adopted for its 2 parts: for the response scales, as well as for formulation of the instruction and the individual scale items.

The optimal level of the 6 characteristics included in the $\mathrm{AD}$ group should oscillate around zero as both high and low levels of job characteristics can cause various types of discomfort to employees and reduce their wellbeing at work. The $\mathrm{AD}$ part includes a 7-point scale, from -3 ("actually does not exist") to +3 ("takes up too much of my time"), with 0 in the middle as the optimal point. The participant's task was to respond to statements concerning various aspects of their job and select a point along the scale. Thus, for example, the employee was asked to complete the following statement: "I believe that social interaction at my workplace... ."

The CE group includes such job characteristics the levels of which should be as high as possible. They are determined using a 7-point agreement scale (from 1 - "I fully disagree" to 7 - "I fully agree") with the items formulated as affirmative sentences describing various aspects of participants' work, e.g., "I know what my future career development prospects are in my company."

The questionnaire was tested in 2 different organizations in the same year. The reliability and validity indicators of the tool were found to be satisfactory [24].

Employee well-being was measured using the Satisfaction With Job Scale [25] which includes 9 items related to satisfaction components such as: co-workers, superiors, working hours, type of tasks, etc. $(\alpha=0.78)$. Respondents determine their level of satisfaction with particular categories on a scale from -5 to +5 . The negative values refer to the level of dissatisfaction and the positive values to the level of satisfaction. The scale also includes value 0 for the neutral level. The questionnaire was used in a number of studies where the level of job satisfaction was determined [26,27]. The scale showed a satisfactory level of reliability and validity.

\section{Description of the sample}

Overall, $71.1 \%$ of the organization's employees participated in the survey (197 out of 277 people). Of those, 169 people worked in the production department and 28 worked in the administration department. The majority of the respondents $(\mathrm{N}=146)$ were men. Women represented a small percentage of the group $(\mathrm{N}=40,11$ missing data). The age of the respondents ranged 20-60 years ( \pm SD 34.61 $\pm 11.21,13$ missing data). The years worked in this organization ranged $1-5(\mathrm{M} \pm \mathrm{SD} 2.25 \pm 2.14$, 20 missing data). Secondary and vocational education was predominant $(66.9 \%)$. The rest of the respondents had either higher $(28 \%)$ or primary education $(5.1 \%)$.

\section{RESULTS}

\section{Relationship of work satisfaction and the job characteristics}

It was considered whether, as the Vitamin Model of wellbeing assumes, the image of job characteristics from the 2 groups is related to the level of employee well-being in different ways [17]. Thus, analyses of the relationship between work satisfaction (a well-being measure) and the results of the Vitamin TAW Questionnaire were carried out.

Firstly, the analysis of the correlation between the level of satisfaction and the evaluation levels of job characteristics in the $\mathrm{AD}$ and $\mathrm{CE}$ groups (Table 1) was performed. As can be seen from Table 1, the job characteristics in the $\mathrm{AD}$ group are very weakly linked to the level of satisfaction experienced by the employees. The majority of these correlations are positive, with Workload constituting an exception. Such correlations may indicate a very weak relationship or a different form of relations.

The correlation matrix for the job characteristics in the CE group indicates that all the characteristics are positively related to the level of perceived satisfaction. In addition, these relationships are strong. The only exception is Sense of security in organization, where the correlation 
Table 1. Relationship of job satisfaction with the level of job characteristics in the "additional decrement" (AD) and "constant effect" (CE) groups 197 employees involved in the Polish automotive production company study, 2016-2017

\begin{tabular}{lc}
\hline \multicolumn{1}{c}{ Dimension } & $\mathrm{p}^{\mathrm{a}}$ \\
\hline The AD group & \\
Personal control & $0.188^{*}$ \\
Demanding supervision & 0.034 \\
Work diversity & $0.172^{*}$ \\
Workload & $-0.203^{* *}$ \\
Social contacts intensity & $0.184^{*}$ \\
Development and evaluation & $0.202^{* *}$ \\
The CE group & \\
Supportive supervision & $0.610^{* *}$ \\
Sense of security in organization & $0.212^{* *}$ \\
Financial compensation & $0.637^{* *}$ \\
Significant social position & $0.492^{* *}$ \\
Organizational ethics & $0.520^{* *}$ \\
Career prospects & $0.566^{* *}$ \\
\hline
\end{tabular}

a Pearson's correlation.

${ }^{*} p \leq 0.05 ;{ }^{* *} p \leq 0.01$.

coefficient is relatively low. Still, its level of significance is very high.

Very weak relationships between the job characteristics in the $\mathrm{AD}$ group and the level of satisfaction as well as the assumption of a non-linear relationship for these variables (indicated in $\mathrm{H} 1$ ) require additional analysis. While verifying this hypothesis, a number of regression analyses were carried out in order to identify the non-linear relationship that would best describe the relationship between the level of job satisfaction and the evaluation of each of the 6 job characteristics of the $\mathrm{AD}$ group.

Table 2 shows the statistics verifying data fit for 3 models: linear, quadratic and cubed. Other models (e.g., S-curve, exponential or logistic models) could not be taken into account as the results of the job satisfaction variable include negative values.

As shown in Table 2, in the following 3 cases: Personal control, Demanding supervision and Workload, the data fit better with the non-linear model than with the linear model.

In the case of Personal control, all 3 models fit the data, but the coefficients of determination $\mathrm{R}^{2}$ achieve significantly higher values for the quadratic and cubic models. In this case, the cubic model has the best fit $\left(\mathrm{R}^{2}>0.5\right)$. On the other hand, the linear model for Demanding supervision does not fit the data at all. The other 2 models fit, with $\mathrm{R}^{2}$ at a very similar level. The empirical data fit all 3 models also in the case of Workload, but the determination coefficients were higher (both at a similar level $>0.2$ ) for models indicating a non-linear dependency. Figure 1 illustrates these relationships graphically. Each chart, apart from empirical data, shows curves representing the 3 models.

As shown in the figure above, the distribution of results is similar to the inverted "U-shaped" line. This confirms the assumption of the Vitamin Model of well-being that too low and too high levels of the AD group characteristics are related to poor well-being of employees. However, this statement refers to only 3 of the 6 job characteristics in the $\mathrm{AD}$ group. For the other characteristics, the scattering of empirical results is ambiguous and the values of determination coefficients are at a too low level to draw any conclusions about similarity to any model of dependencies.

Although the analysis of the correlation of job satisfaction with the CE group of job characteristics confirmed a significant and high level of a positive relationship, an analysis was done to determine whether the distribution of empirical data was a reflection of the linear relationship between variables. Therefore, for each job characteristic, a variance analysis was performed to check the fit of the linear model. Table 2 shows the obtained results, which confirm the linear relationship of all CE group job characteristics with job satisfaction. Therefore, in accordance with $\mathrm{H} 2$, it can be stated that the higher the employees evaluate these job characteristics, the more satisfaction they derive from work. 
Table 2. Models summary - relationships of the job satisfaction and job characteristics in the "additional decrement" (AD) and "constant effect" (CE) groups 197 employees involved in the Polish automotive production company study, 2016-2017

\begin{tabular}{|c|c|c|c|c|c|c|c|c|c|}
\hline \multirow{2}{*}{$\begin{array}{l}\text { Job satisfaction/characteristics } \\
\text { relationship }\end{array}$} & \multicolumn{5}{|c|}{ Models summary } & \multicolumn{4}{|c|}{ Parameter estimate } \\
\hline & $\mathrm{R}^{2}$ & $\mathrm{~F}$ & df1 & $\mathrm{df} 2$ & $\mathrm{p}$ & constant & b1 & b2 & b3 \\
\hline \multicolumn{10}{|l|}{ The AD group } \\
\hline \multicolumn{10}{|l|}{ Personal control } \\
\hline linear & 0.265 & 85.114 & 1 & 195 & 0.000 & 14.617 & 2.092 & & \\
\hline quadratic & 0.446 & 94.487 & 2 & 194 & 0.000 & 18.617 & 0.182 & -0.234 & \\
\hline cubic & 0.582 & 108.471 & 3 & 193 & 0.000 & 24.752 & 1.301 & -0.499 & -0.024 \\
\hline \multicolumn{10}{|l|}{ Demanding supervision } \\
\hline linear & 0.001 & 0.273 & 1 & 195 & 0.602 & 12.022 & 0.148 & & \\
\hline quadratic & 0.247 & 38.491 & 2 & 194 & 0.000 & 18.371 & -0.621 & -0.279 & \\
\hline cubic & 0.284 & 30.954 & 3 & 193 & 0.000 & 19.737 & 0.487 & -0.351 & -0.015 \\
\hline \multicolumn{10}{|l|}{ Work diversity } \\
\hline linear & 0.032 & 7.768 & 1 & 195 & 0.006 & 6.954 & 0.476 & & \\
\hline quadratic & 0.032 & 3.927 & 2 & 194 & 0.021 & 7.371 & 0.455 & -0.005 & \\
\hline cubic & 0.036 & 2.893 & 3 & 193 & 0.036 & 7.576 & 0.683 & -0.012 & -0.001 \\
\hline \multicolumn{10}{|l|}{ Workload } \\
\hline linear & 0.094 & 24.596 & 1 & 195 & 0.000 & 21.715 & -1.745 & & \\
\hline quadratic & 0.259 & 41.087 & 2 & 194 & 0.000 & 22.111 & 1.290 & -0.436 & \\
\hline cubic & 0.261 & 27.484 & 3 & 193 & 0.000 & 22.809 & 1.156 & -0.487 & 0.006 \\
\hline \multicolumn{10}{|l|}{ Social contacts intensity } \\
\hline linear & 0.060 & 15.110 & 1 & 195 & 0.000 & 9.687 & 1.136 & & \\
\hline quadratic & 0.063 & 7.885 & 2 & 194 & 0.000 & 9.365 & 1.423 & 0.033 & \\
\hline cubic & 0.064 & 5.328 & 3 & 193 & 0.001 & 9.794 & 1.471 & 0.003 & -0.002 \\
\hline \multicolumn{10}{|l|}{ Development and evaluation } \\
\hline linear & 0.097 & 25.476 & 1 & 195 & 0.000 & 13.098 & 1.073 & & \\
\hline quadratic & 0.100 & 12.996 & 2 & 194 & 0.000 & 13.229 & 0.807 & -0.021 & \\
\hline cubic & 0.101 & 8.744 & 3 & 193 & 0.000 & 14.023 & 0.739 & -0.061 & -0.002 \\
\hline \multicolumn{10}{|l|}{ The CE group (only linear analysis) } \\
\hline Supportive supervision & 0.261 & 83.446 & 1 & 195 & 0.000 & -23.160 & 1.113 & & \\
\hline Sense of security in organization & 0.176 & 50.421 & 1 & 195 & 0.000 & -33.188 & 1.212 & & \\
\hline Financial compensation & 0.230 & 70.499 & 1 & 195 & 0.000 & -21.640 & 1.082 & & \\
\hline Significant social position & 0.203 & 60.037 & 1 & 195 & 0.000 & -25.207 & 1.164 & & \\
\hline Organizational ethics & 0.215 & 64.550 & 1 & 195 & 0.000 & -28.412 & 1.600 & & \\
\hline Career prospects & 0.223 & 67.843 & 1 & 195 & 0.000 & -13.555 & 1.504 & & \\
\hline
\end{tabular}



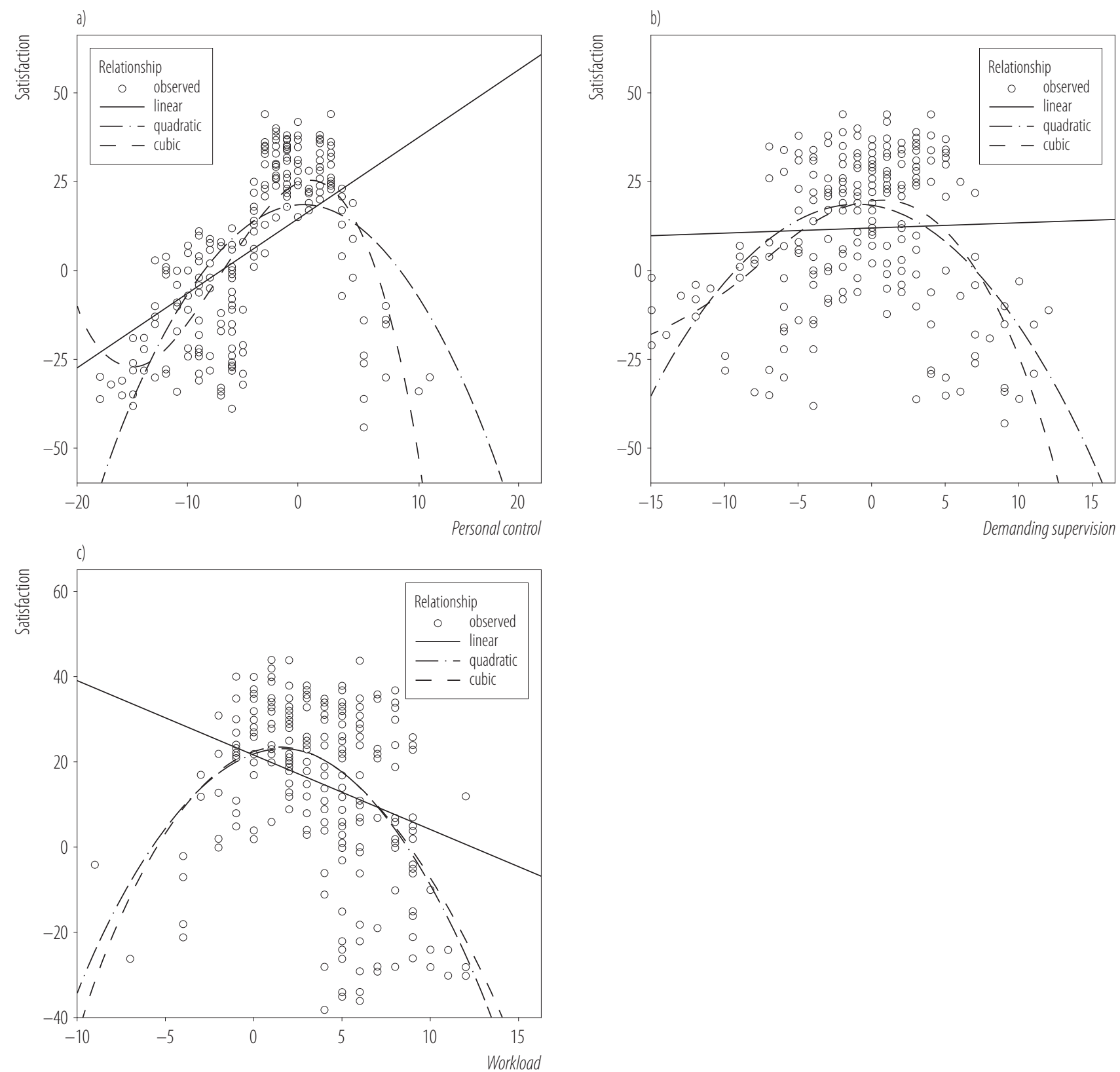

Aggregated data of the analyzed variables.

Figure 1. Relationship between job satisfaction and a) Personal control, b) Demanding supervision, and c) Workload in 197 employees involved in the Polish automotive production company study, 2016-2017

\section{DISCUSSION}

The main issue analyzed in this project was the verification of assumptions of the curvilinear nature of the relationship between well-being and some of the job characteristics of the Vitamin Model. Analyses have shown that the non-linear relationship can be confirmed for 3 of the 6 characteristics from the first group: Personal control, Demanding supervision and Workload. The other 3: Work diversity, Social contact intensity, Development and evaluation do not show such a relationship. Perhaps the employ- 
ees of the tested - after all production - organization do not experience very different levels of these job characteristics. From an interview with an employee of the human resources department, it is known that in this company production workers have some influence on the organization of their working time (e.g., the schedule in a month), but they have no influence on diversifying their work. This may be one of the reasons why the distributions of scores, e.g., for the Personal control and Work diversity differ in terms of their relationship with job satisfaction.

Another reason for the lack of a clearly non-linear relationship with satisfaction for some scales in the $\mathrm{AD}$ group may also be the low importance of these characteristics for the respondents. It is worth quoting here data from another study conducted in the same company (not yet published), in which employees estimated the subjective importance of the 12 job characteristics of the Vitamin Model. The results can be compared using the dominants obtained for each of the scales. The lower the value of the dominant, the more important this scale is for the respondent. The dominants are set to 1 for Personal control, and to 2 for Demanding supervision and Workload, while in the case of Work diversity, Social contact intensity, and Development and evaluation they are set to 11,7 and 8 , respectively. A significant difference in the importance of the scales can thus be noticed. The more important ones have a curvilinear relationship with satisfaction and the less important ones do not correlate so clearly with job satisfaction. Taking into account the above-mentioned explanations, it can be assumed, however, that to some extent the hypothesis about the non-linear relationship of job characteristics in the $\mathrm{AD}$ group with job satisfaction has been confirmed.

The obtained results cannot be explained on the basis of classic models such as the JCM by Hackman and Oldham [14] or the JD-C model by Karasek [15,16], which was also mentioned in the first part of the article. It is worth noting, however, that in the modified Job DemandControl-Support model (JD-C-S) by Karasek and Theo- rell [28], there is an area directly related to resources. Support, understood as social support available in an organization, can be treated as a kind of organizational resource after all. In the Vitamin Model, one can find the Supportive supervision dimension related to the support provided by the manager. However, since the remaining job characteristics of the CE group can also be treated as other kinds of resources (not as a support), the most relevant theoretical model seems to be the JD-C model [2].

It can, therefore, be assumed that the job characteristics whose level - too high or too low - is associated with dissatisfaction and stress, as well as other negative consequences, represent demands at work. On the other hand, these features - which bring more positive effects when their levels are higher - represent job resources which help meet the demands of the job. The example of associated (similar) characteristics from 2 different groups, i.e., demanding and supportive supervision, shows that the first type can hardly be considered a resource. Workers often have to cope with this type of supervision, rather than use it in terms of assistance and support. Supportive supervision, on the other hand, is a characteristic of work and superiors which does not need to be dealt with, as it helps at work and builds employee's resources.

The results obtained for the CE group are not surprising and they fully confirm the theoretical assumptions. All job characteristics in this group support a high level of job satisfaction. Undoubtedly, in the context of the JD-R model $[28,29]$, each of these features can be treated as an organizational resource. From the practical point of view, the conclusion of these results is very simple. Since one cannot overdose on these characteristics, the organization should always strive to improve these work features. Even if they are at a high level, maintaining or even further increasing the intensity of the features from this group will have a positive impact on the well-being of employees. Moreover, it should be noted that the mechanisms of impact of particular job characteristics ("vitamins") 
are probably varied and do not have to be universal. The effect of vitamins on well-being at work can vary greatly depending on the industry, organizational culture, and even the management style of leaders in these organizations. Is it possible that, in some special cases, the job characteristics from the AD group lose their specific character and enter into a linear relationship with measures of well-being at work? This is, of course, a very bold thesis, but probably worth considering. This statement is, by all means, hypothetical. The research was conducted in an automotive company and the results cannot be generalized. However, this is some contribution to further research that could verify the universality of the Vitamin Model. The confirmation of this thesis requires a lot of research conducted in various industries. Only then would it be possible to objectively verify this model.

It is also worth considering the role of the subjective importance of particular job characteristics for employees in the organization. Perhaps it, but not the industry itself, can modify the relationship between a given job characteristic and a measure of perceived well-being. It may be worth considering a study procedure involving such a variable (subjective meaning) as a mediator or moderator of the relationship between job characteristics and well-being.

In the analyzed case (a specific organization from the automotive industry), most of the respondents belonged to the group of production and administrative employees. In this type of work, development, career, autonomy, variability and work creativity are relatively limited. In the case of people working in a creative, variable, autonomous way (e.g., in creative business, IT and others), the structure of the relationship between the characteristics of work and the well-being of employees could turn out to be different. Thus, the universality of the model may be limited and it may be much more interactive in the sense of the relationship between the objective nature of work and the industry, employees' perception of the job characteristics in a specific organization and their well-being. However, it should be emphasized that even taking into account the influence of the contextual factors mentioned above, the Vitamin Model of job characteristics is undoubtedly related to job satisfaction. Therefore, diagnosing the job characteristics assessed by employees can be extremely useful in enhancing their well-being. However, it requires a committed and responsible attitude, and often also action (intervention) on the part of the management.

\section{CONCLUSIONS}

Currently, the need to ensure the well-being of employees seems obvious in the perception of people as the crucial resource of organizations. Moreover, many results of the research suggest also an equal importance of this mental state of employees for the functioning of the entire organization. Meta-analysis of various research carried out in this context [8] shows that the well-being of employees contributes to a more effective use of working time, increased quality of work, better interpersonal relationships at work, less frequent and better resolved conflicts, loyalty to the employer, civic attitude towards the organization, increased organization's innovation, customer satisfaction, less employee turnover, less work absences, and safer work.

Since the well-being of employees brings so many benefits to the organization, actions aimed at raising and nurturing the well-being of its employees should become the norm. It seems that the results and conclusions given above can help achieve this goal in many different organizations.

The research presented above shows that the assessment of job characteristics by employees is significantly related to their satisfaction. More detailed knowledge, such as that which results from this research, goes beyond the simple postulate of creating a "good and friendly 
workplace." Leaders should focus on specific characteristics of work that may be significant and where changes could increase job satisfaction (e.g., supportive supervision). At the same time, leaders should put in significantly less effort or even ignore actions that are irrelevant or may reduce employee satisfaction (e.g., excessive work diversity). It should also be stressed that the hypothesis of spontaneous, natural development of the organization towards a positive organization is strongly influenced by many assumptions and conditions, also external (e.g., market-based). Therefore, it seems advisable that repeated measurement studies be carried out in projects with the use of specific interventions or other significant changes in the organization itself or its environment.

These results clearly demonstrate the need for reflection, as well as evidence-based and data-driven changes in human management and the creation of positive organizations, including changes that are better tailored to particular needs of specific worker groups.

\section{Limitations}

The basic limitation of the presented research is the analysis of only one organization. Moreover, in this type of company, employees have a very different scope and content of work, depending on the department in which they are employed and their role in the organization (i.e., managerial or not managerial). Other analyses, carried out in this company as part of a larger project, showed significant differences in the image of job characteristics and well-being levels between employee groups based on work content and the role within the organization. In addition, the job characteristics evaluation profile given by employees is probably quite specific to the industry itself, and the type and culture of an organization. Comparative analyses of organizations across different industries, types and cultures of organizations would, therefore, be highly recommended.

\section{REFERENCES}

1. Deci EL, Ryan RM. Hedonia, eudaimonia, and well-being: An introduction. J Happiness Stud. 2008;9:1-11, https://doi. org/10.1007/s10902-006-9018-1.

2. Waterman AS. Two conceptions of happiness: Contrasts of personal expressiveness (eudaimonia) and hedonic enjoyment. J Pers Soc Psychol. 1993;64(4):678-91, https://doi. org/10.1037/0022-3514.64.4.678.

3. Diener E. Subjective well-being. Psychol Bul. 1984;95(3): $542-75$.

4. Ryff CD. Happiness is everything, or is it? Explorations on the meaning of psychological well-being. J Pers Soc Psychol. 1989;57:1069-81.

5. Seligman ME. Authentic happiness. New York, NY: Free Press; 2002.

6. Diener E, Suh M, Lucas E, Smith H. Subjective well-being: Three decades of progress. Psychol Bul. 1999;25(2):276302, https://doi.org/10.1037/0033-2909.125.2.276.

7. Dodge R, Daly A, Huyton J, Sanders L. The challenge of defining wellbeing. Int J Wellbeing. 2012;2:222-35, https:// doi.org/10.5502/ijw.v2i3.4.

8. Ford M, Cerasoli Ch, Higgins J, Decesare A. Relationships between psychological, and behavioral health and work performance: A review and meta-analysis. Work Stress. 2011;25(3):185-204, https://doi.org/10.1080/02678373.2011. 609035 .

9. McCarthy JM, Trougakos JP, Cheng BH. Are anxious workers less productive workers? It depends on the quality of social exchange. J Appl Psychol. 2016;101(2):279-91, https:// doi.org/10.1037/apl0000044.

10. Chung-Yan GA. The nonlinear effects of job complexity and autonomy on job satisfaction, turnover, and psychological well-being. J Occup Health Psychol. 2010;15:237-51, https://doi.org/10.1037/a0019823.

11. Meyerding GH. Job characteristics and job satisfaction: A test of Warr's Vitamin Model in German horticulture. The Psychol-Manag J. 2015;18(2):86-107, https://doi.org/10.1037/ mgr0000029. 
12. Rydstedt L, Ferrie J, Head J. Is there support for curvilinear relationships between psychosocial work characteristics and mental well-being? Cross-sectional and long-term data from the Whitehall II study. Work Stress. 2006;20(1):6-20, https://doi.org/10.1080/02678370600668119.

13. Warr P. Jobs and job-holders: Two sources of happiness and unhappiness. In: Boniwell I, David SA, Ayers AC, editors. The Oxford handbook of happiness. Oxford: Oxford University Press; 2013. p. 733-50.

14. Fried Y, Ferris GR. The validity of the Job Characteristics Model: A review and meta-analysis. Pers Psychol. 1987;40:287322, https://doi.org/10.1111/j.1744-6570.1987.tb00605.x.

15. Karasek R. Job demands, job decision latitude, and mental strain: Implications for job redesign. Admin Sci Quart. 1979;24(2):285-308.

16. Van Der Doef M, Maes S. The Job Demand-Control Model and psychological well-being: A review of 20 years of empirical research. Work Stress. 1999;13(2):87-114, https://doi. org/10.1080/026783799296084.

17. Warr P. Environmental "vitamins", personal judgements, work values, and happiness. In: Cartwright S, Cooper SL, editors. The Oxford handbook of organizational well-being. New York, Oxford: Oxford University Press; 2009. p. 57-87.

18. Warr P, Clapperton G. The joy of work. East Sussex: Routledge; 2010.

19. De Jonge J, Schaufelli W. Job characteristics and employee wellbeing: A test of Warr's Vitamin Model in health care workers using structural equation modeling. J Organ Behav. 1998;19(4): 387-407, https://doi.org/10.1002/(SICI)1099-1379(199807)19: 4<387::AID-JOB851>3.0.CO;2-9.

20. Jeurissen T, Nykliček I. Testing the Vitamin Model of job stress in Dutch health care workers. Work Stress. 2001;15(3): 254-64, https://doi.org/10.1080/02678370110066607.
21. Irving PG, Montes SD. Met expectations: The effects of expected and delivered inducements on employee satisfaction. J Occup Organ Psychol. 2009;2(2):431-51.

22. Mäkikangas A, Feldt T, Kinnunen U. Warr's scale of job-related affective well-being: A longitudinal examination of its structure and relationships with work characteristics. Work Stress. 2007;21(3):197-210, https://doi.org/10.1080/026783 70701662151.

23. Cameron KS, Dutton JE, Quinn RE. Foundations of positive organizational scholarship: Introduction. In: Cameron KS, Dutton JE, Quinn RE, editors. Positive organizational scholarship: Foundations of a new discipline. San Francisco: Berrett-Koehler; 2002. p. 3-13.

24. Borkowska A, Czerw A. [Empirical verification of the Vitamin Model of well-being at work]. Humanizacja Pracy [Work Hum]. 2015:1:183-99. Polish.

25. Bajcar B, Borkowska A, Czerw A, Gąsiorowska A. Satysfakcja z pracy w zawodach z misją społeczną: psychologiczne uwarunkowania [Job satisfaction in occupations with a social mission: Psychological causes]. Gdańsk: Gdańskie Wydawnictwo Psychologiczne; 2011.

26. Czerw A. Diagnosing well-being in work context - Eudemonic Well-Being in the Workplace Questionnaire. Curr Psychol. 2019;38:331-46, https://doi.org/10.1007/s12144017-9614-8.

27. Czerw A, Borkowska A. [Work as a field of social mission accomplishment]. Psychol Społ. 2010;5(4):303-15. Polish.

28. Fila MJ. The job demands, control, support model: Where are we now? TKM Int J Res Manag. 2016;1:15-44.

29. Bakker AB, Demerouti E. The Job Demands-Resources model: State of the art. J Manag Psychol. 2007;22:309-28, https://doi.org/10.1108/02683940710733115.

This work is available in Open Access model and licensed under a Creative Commons Attribution-NonCommercial 3.0 Poland License - http://creativecommons.org/ licenses/by-nc/3.0/pl/deed.en. 